\title{
LETTER
}

\section{Carboxyhemoglobin levels in medical intensive care patients}

\author{
Matthew E Cove* and Michael R Pinsky \\ See related research by Fazekas et al., http://ccforum.com/content/16/1/R6
}

We read with interest the study by Fazekas and colleagues demonstrating that lower levels of carboxyhemoglobin are associated with increased mortality in critically ill patients [1]. This observation is of interest since prior studies have shown that carbon monoxide $(\mathrm{CO})$, the silent killer, may actually have therapeutic applications. $\mathrm{CO}$ suppresses inflammation and apoptosis, reduces pulmonary hypertension and potentially protects against multiple organ injury in animal models [2]. The fact that average carboxyhemoglobin levels are slightly lower in ICU nonsurvivors compared with survivors $(1.5 \%$ vs. $1.6 \%, P=0.003)$ supports the findings of animal studies.

However, an important confounding factor deserves consideration. ICU nonsurvivors are sicker and therefore likely to receive a higher $\mathrm{FiO}_{2}$ than ICU survivors. Most hospitals supply oxygen from liquid oxygen, whereas medical air is supplied by compressing filtered environmental air. Previous work at Pittsburgh has shown that nitric oxide (NO) contamination of compression medical air resulted in a clinically detectable difference in $\mathrm{NO}$ levels that directly altered oxygenation [3]. The air in most major cities is also contaminated with $\mathrm{CO}$ [4] consequent to fossil fuel combustion. Medical air thus contains varying amounts of $\mathrm{CO}$, as well as other pollutants. Patients receiving a higher $\mathrm{FiO}_{2}$ receive less medical air, and are therefore exposed to less occult $\mathrm{CO}$. This reduction in medical air might explain the small differences in carboxyhemoglobin seen in the present study, just as it explained the lower NO levels. Until this confounding influence is accounted for, the prior observations may merely reflect this $\mathrm{CO}$ washout phenomenon.

\section{Authors' response}

Andreas S Fazekas, Marlene Wewalka, Christian Zauner and Georg-Christian Funk

We kindly thank Cove and Pinsky for their reply to our study. Based on the CO content of medical air and oxygen, they provide a potential explanation for the observed differences in carboxyhemoglobin levels in ICU survivors and nonsurvivors described in our study. We regret that the absence of data on the $\mathrm{FiO}_{2}$ fractions used in our study population does not enable us to further test the relation between the amount of oxygen used and carboxyhemoglobin levels.

Sheu and colleagues found an increased activity of the heme oxygenase- 1 gene to be associated with a reduced risk for the development of adult respiratory distress syndrome [5]. This finding leads us to assume that there is - at least in part - a genetic basis to the differences in

${ }^{*}$ Correspondence: coveme@upmc.edu

Department of Critical Care Medicine, 606 Scaife Hall, 3550 Terrace Street, University of Pittsburgh, Pittsburgh, PA 15261, USA carboxyhemoglobin levels and mortality. Furthermore, Melley and colleagues found elevated maximum carboxyhemoglobin levels to be associated with an increased mortality in critically ill patients following cardiothoracic surgery [6] - which would potentially argue against the hypothesis by Cove and Pinsky. Of note, however, this finding was not reproduced in our study.

\section{Abbreviations}

$\mathrm{CO}$, carbon monoxide; $\mathrm{FiO}_{2}$, fraction of inspired oxygen; $\mathrm{NO}$, nitric oxide.

\section{Acknowledgements \\ The present work was supported in part by NIH grants HL067181 and HL073198.}

\section{Competing interests}

The authors declare they have no competing interests.

Published: 16 February 2012

\section{References}

1. Fazekas AS, Wewalka M, Zauner C, Funk GC: Carboxyhemoglobin levels in medical intensive care patients: a retrospective, observational study. Crit Care 2012, 16:R6. 
2. Foresti R, Bani-Hani MG, Motterlini R: Use of carbon monoxide as a therapeutic agent: promises and challenges. Intensive Care Med 2008, 34:649-658.

3. Tan PS, Genc F, Delgado E, Kellum JA, Pinsky MR: Nitric oxide contamination of hospital compressed air improves gas exchange in patients with acute lung injury. Intensive Care Med 2002, 28:1064-1072.

4. EPA Air Trends Fact Book. Air Quality Statistics by City 2010 [http://epa.gov/airtrends/pdfs/cbsafactbook2010.pdf]

5. Sheu CC, Zhai R, Wang Z, Gong MN, Tejera P, Chen F, Su L, Thompson BT, Christiani DC: Heme oxygenase-1 microsatellite polymorphism and haplotypes are associated with the development of acute respiratory distress syndrome. Intensive Care Med 2009, 35:1343-1351.
6. Melley DD, Finney SJ, Elia A, Lagan AL, Quinlan GJ, Evans TW: Arterial carboxyhemoglobin level and outcome in critically ill patients. Crit Care Med 2007, 35:1882-1887.

doi:10.1186/cc11163

Cite this article as: Cove ME, Pinsky MR: Carboxyhemoglobin levels in medical intensive care patients. Critical Care 2012, 16:411. 